\title{
FACT-CHECKING EN LATINOAMÉRICA. TIPOLOGÍA DE CONTENIDOS VIRALES DESMENTIDOS DURANTE LA PANDEMIA DEL CORONAVIRUS
}

\section{FACT-CHECKING IN LATIN AMERICA. TYPOLOGY OF VIRAL CONTENTS DISMISSED DURING THE CORONAVIRUS PANDEMIC}

\author{
(1) (8) $\mathbb{R}^{\mathbb{R}}$ Leticia Quintana Pujalte1. Universidad de Málaga. España.
}

María Florencia Pannunzio². Universidad Nacional del Nordeste. Argentina.

\section{Cómo citar el artículo:}

Quintana Pujalte, L. y Pannunzio, M. F. (2021). Fact-checking en latinoamérica.

Tipología de contenidos virales desmentidos durante la pandemia del coronavirus.

Revista de Ciencias de la Comunicación e Información, 26, 27-46.

http://doi.org/10.35742/rcci.2021.26.e178

\section{RESUMEN}

Una de las peores facetas de la pandemia por el coronavirus en el ámbito de los estudios de comunicación fue la infodemia, esto es, la distribución viral de noticias falsas. En este marco, organizaciones que trabajan con calidad informativa, decidieron inaugurar una red de fact-checkers o chequeadores de información en América Latina denominado LatamChequea. A partir de los datos proporcionados por la plataforma, que abarca el periodo comprendido entre el 27 de febrero y el 25 de septiembre de 2020, se analizan los contenidos virales y desmentidos por esta red de verificadores con el fin de problematizar las lógicas latentes de las desinformaciones. Los resultados indican que hay temáticas que se viralizan de manera transnacional y el trabajo colaborativo de los fact-checkers permite agilizar las acciones de advertencia a los medios y a la ciudadanía frente a la desinformación. En el plano de la discusión, se considera necesario un enorme esfuerzo en la concienciación sobre contenidos que se comparten en redes sociales, así como una discusión sincera sobre la regulación o no de estos contenidos. Se concluye que en el contexto de crisis sanitaria, los contenidos de tipo político encuentran altos niveles de expresión entre los contenidos

\footnotetext{
${ }^{1}$ Leticia Quintana Pujalte: Doctora en Comunicación con Mención Internacional (UMA-España), investigadora en las líneas de comunicación política, ciberactivismo, estudios sobre framing y opinión pública. Personal de investigación contratado en la UMA, autora de artículos científicos y capítulos de libro. Email: I.quintanapujalte@uma.es

${ }^{2}$ María Florencia Pannunzio: Doctora en Comunicación (UNLP-Arg). Licenciada en Comunicación Social (UNNE-Arg). Investigadora del Centro de Estudios Sociales de la Universidad Nacional del Nordeste (UNNE) en temáticas de juventudes, participación y apropiación de tecnologías digitales. Docente en las cátedras Teorías de la comunicación social 1 e Investigación en comunicación de la Licenciatura en comunicación social (Facultad de Humanidades, UNNE). Email: florencia.pannunzio@comunidad.unne.edu.ar
}

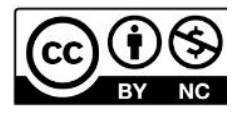


desmentidos. Los actores políticos de relevancia muchas veces son partícipes de la difusión de contenidos falsos, y los medios demuestran también ser parte de la misma debilidad de verificación que se observa en las redes sociales.

PALABRAS CLAVE: fake news, fact-checking, red de verificación, análisis de contenido, Latinoamérica, coronavirus, desinformación, salud.

\begin{abstract}
One of the worst faces of the coronavirus pandemic in the field of communication studies was the infodemic, that is, the viral distribution of fake news. In this scenario, organizations that work with informational quality decided to start a network of information checkers in Latin America called LatamChequea. Based on the data provided by the platform, the viral and denied content is analyzed in the period between February 27 and September 25, 2020. The analysis is carried out in order to problematize the latent logic of misinformation. The results indicate that there are issues that are viralized transnationally and the collaborative work of fact-checkers allows speeding up actions to warn the media and citizens against misinformation. At the level of discussion, an enormous effort is considered necessary to raise awareness about content that is shared on social networks, as well as a sincere discussion about the regulation or not of this content. It is concluded that in the context of the health crisis, political content finds high levels of expression among the content that was denied. Relevant political actors are often participants in the dissemination of false content, and the media also prove to be part of the same verification weakness that is observed in social networks.
\end{abstract}

KEYWORDS: fake news, fact-checking network, content analysis, Latin America, coronavirus; disinformation; health.

\title{
1. INTRODUCCIÓN
}

Uno de los temas que más debate ha provocado durante la pandemia es el modo en que se viralizaron las noticias que desinforman, provocando justamente lo contrario de lo que debería ser su razón de ser: informar a la ciudadanía. El público queda muchas veces expuesto a la trampa de encontrarse con noticias sobre las que no puede chequear la veracidad de la información a la que está expuesto.

En momentos de crisis la ciudadanía busca informarse más que en tiempos tranquilos. Durante esta pandemia ocasionada por el Covid-19, los niveles de audiencia aumentaron y así lo comprueba un informe del Reuters Institute publicado en abril de 2020, respecto de hábitos de consumo en Alemania, Argentina, Corea del Sur, España, los Estados Unidos y el Reino Unido (Nielsen, et al., 2020).

Ante esta gran demanda informativa también surgieron y se distribuyeron contenidos sin bases científicas ni correlato con la realidad, generando más ansiedad y preocupación en la ciudadanía. Está claro que la desinformación y las noticias falsas fueron, son y serán parte de la lucha que tiene el periodismo de calidad para poder cumplir con su deber de informar (Owen, 2018). La defensa y protección de contenidos 
fiables no es menor, porque en los sistemas democráticos la ciudadanía tiene el derecho a la información para tomar mejores decisiones cívicas y políticas.

De cara a estas problemáticas, que tienen un potencial impacto en el sistema político, organizaciones de verificación de información o fact-checking llevan poco más de una década haciendo el esfuerzo por desmentir contenidos que se hacen públicos a través de medios y redes sociales. El foco del presente estudio está puesto en estas plataformas de verificación y el propósito es doble: En primer lugar, se analizaron los contenidos que se hicieron virales en América Latina a partir del análisis de las informaciones desmentidas por el grupo de fact-checking denominado LatamChequea, creado formalmente en febrero de 2020. En segundo lugar, a partir de estos contenidos chequeados y desmentidos, se buscará establecer una tipología de aquellas (des)informaciones que operaron durante los primeros ocho meses de la crisis sanitaria para identificar los perfiles que caracterizan a estos bulos virales (Pérez-Dasilva, et al., 2020).

La investigación se justifica por el interés y preocupación que genera la viralización de informaciones falsas a nivel global, así como el compromiso que se debe tener con la ciudadanía para que accedan a informaciones veraces o que, en su defecto, cuenten con las herramientas para identificar bulos informativos.

Se considera que este ejercicio permitirá conocer el estado actual de las noticias que han sido desmentidas por LatamChequea, con el fin de problematizar las lógicas latentes de estas desinformaciones. A partir de los datos proporcionados por la red, que abarca el periodo comprendido entre el 27 de febrero y el 25 de septiembre de 2020, se realiza un estudio desde el método de análisis de contenido, con el fin de identificar tipologías de contenidos virales durante la crisis sanitaria. Esta metodología se inspira en estudios como los de Brennen et al. (2020) y Salaverría et al. (2020).

\subsection{Los problemas de la desinformación en el ecosistema mediático actual}

Las fake news, noticias falsas, bulos o desórdenes de información, como denomina Wardle (2019), representan un problema cada vez más notable a escala global. Estos fenómenos de circulación de información falsa o errónea no son nuevos, y el vínculo entre (des)información, engaño, convencimiento, estrategia y poder, tiene ya varios siglos. Algunos ejemplos los destaca Romero-Rodríguez (2013) en obras clásicas. En La Odisea, Homero relata una particular estrategia militar que se basó en el engaño. El famoso caballo de Troya, que fue dado como ofrenda a la ciudad, pero con soldados prestos a la batalla escondidos en su interior y que determinaron la caída de la ciudad fortificada. Más adelante en la historia, también se puede hallar otro texto clásico de estrategia militar El Arte de la Guerra de Sun Tzu, que destaca la importancia del convencimiento de las propias tropas a partir de engaños, relatos o mitos, para asegurarse su acompañamiento en las operaciones militares.

En la historia más reciente, los artilugios para la conducción de los discursos que se hacen públicos se hicieron relevantes también para la estrategia política. El Partido Comunista Soviético fue uno de los grandes actores políticos que llevaron adelante estas acciones de propaganda, engaño, apelación a la emoción y la construcción de un relato que frecuentemente tenía poco contacto con la realidad. Esa necesidad de 
control del mensaje con criterios que benefician al poder también pudo observarse en la gestión del Ministro de Propaganda e Información del régimen Nazi (entre 19331945), Joseph Goebbels. El reconocimiento de la importancia de la manipulación de la opinión pública se plasma en los "principios" que dejó este personaje tristemente célebre de la historia universal. Su estrategia se basaba en el control absoluto de los medios de comunicación, el control de todo tipo de información vinculadas al régimen y, por supuesto, la censura (Dobb, 1950).

Estos procesos de dominación y manipulación que favorecen al poder a partir de artimañas fueron denunciados durante décadas por sectores vinculados al marxismo, como los referentes de la Escuela de Frankfurt. Marcuse señala que el poder se vale de técnicas de engaño y confusión para generar una mayor simpatía en la población y así mantener su posición privilegiada, sin disensos, gracias al control de los medios de comunicación (Marcuse, 1964). El autor realiza un profundo análisis sobre el rol de los medios en este proceso de construcción de un relato que termina por alienar a las audiencias, dejándolas indefensas ante el poder.

Para estos analistas de hechos sociales previos al surgimiento y consolidación de Internet, el papel de los medios masivos de comunicación era fundamental para mantener el statu quo de los actores políticos. Otros estudios críticos más actuales señalan que los medios se erigen como actores políticos en sí mismos, con conciencia plena de su capacidad de influencia en la opinión pública (Schiller, 1987).

Aunque hay mucho por decir respecto de los abordajes que relacionan la circulación de los mensajes falsos dentro de la esfera pública, la comunicación de éstos y las relaciones de poder que los constituyen, se puede resumir que los enfoques teóricos que tratan estos desórdenes informativos entre el siglo XIX y el siglo XX son tres: el paradigma de la masificación social; el paradigma de la manipulación propagandística y el de la mediatización espectacular (Pérez-Tornero et al., 2018).

A finales del siglo XIX y principios del siglo XX se dan los procesos de masificación en las sociedades modernas, que se pueden describir como escenarios pre-democráticos y pre-mediáticos: "El desarrollo mediático es incipiente y depende de sistemas mecánicos como la imprenta y el papel, es decir, no disponen de medios de comunicación basados en la electricidad" (Pérez Tornero et al, 2018, pp. 216-217). En este momento histórico se sitúan los estudios sobre el alma de las masas, la subordinación de la individualidad a la lógica de la masa, lo que provoca la pérdida de la individualidad y el sometimiento a la unidad mental de ésta. La capacidad de sugestión y la apelación al instinto supera al individuo y a la razón (Le Bon, 1947). O los de Freud (2013), quien busca la explicación psicológica de la modificación psíquica que la influencia de la masa impone al individuo. Señala que en la esencia del alma colectiva existen también relaciones amorosas que dan cohesión a la masa, por lo que el individuo englobado en la masa renuncia a lo que le es personal y se deja sugestionar por los otros, y lo hace por sentir en él la necesidad de hallarse de acuerdo con ellos y no en oposición a ellos, esto es, por amor a los demás. A este periodo de análisis lo caracterizan abordajes que provienen del psicoanálisis y la sociología.

El paradigma de la manipulación propagandística se sitúa desde el principio y hasta mediados del siglo XX, caracterizado por el periodo de entreguerras y la masificación 
de los avances tecnológicos. Tomaron impulso estudios como los de Lasswell (1927); Bernays (1928) o Lazarsfeld (2011), desde donde analizaron los efectos que tenía en la ciudadanía la propaganda y la desinformación en regímenes autoritarios, así como durante campañas electorales de sistemas democráticos. En este periodo, Bryant (1953) se enfoca en la propaganda y destaca los rasgos engañosos que la constituyen para persuadir a los públicos, la define como: "Cualquier retórica parcial o engañosamente empleada, al servicio de técnicas 'antirrazón' o 'pseudorrazón', tales como la sugestión, la reiteración, la sustitución imaginativa, la irrelevancia verbal, el acoso emocional y pseudológico, la exclusión de las ideas competidoras y el cortocircuito o by-pass del juicio informado" (Bryant, 1953, p. 417).

El tercer paradigma es el de la mediatización espectacular. Corresponde a finales del siglo XX donde las sociedades ya se encuentran completamente atravesadas por la lógica del consumo y a las órdenes del capital, catapultadas por un sistema mediático arraigado y mundialmente accesible. El discurso público se comercializa como un producto más de la industria, y se manifiesta una fuerte conexión con la publicidad y el márketing, lo que provoca que estos discursos políticos se transformen según las normas del espectáculo (Debord, 1967). La televisión jugó un papel fundamental para el desarrollo de este proceso de espectacularización, que entre otros efectos, debilita la línea que separa lo público de lo privado y la información del entretenimiento (Delli Carpini y Williams, 2011).

Más allá de los abordajes particulares, lo que caracteriza a estos paradigmas es el reconocimiento de que el discurso público que apela a la emoción, a la afectividad y pocas veces a la razón o, incluso, a la realidad, tienen un fuerte arraigo en el sistema sociopolítico; a su vez, su supervivencia se configura según el ecosistema que lo contenga. Cabe remarcar que a diferencia de lo que esos ecosistemas de la comunicación proponían, el escenario actual de la web 2.0 y 3.0 sustituye el sistema de comunicación unidireccional por uno bidireccional, donde las redes socio-digitales aparecen como protagonistas de los cambios. Allí, los agentes pasan de ocupar un rol pasivo-receptivo, a uno en el que pueden emitir y recibir, producir o consumir.

Luciano Galup (2019) plantea que el gran desafío que presentan las redes sociodigitales se vinculan con la reconfiguración del modelo hegemónico de la mediación entre la política y la sociedad, que desde la década de 1980 y durante casi treinta años tuvo como protagonista a los medios de comunicación tradicionales en general (radio, prensa gráfica) y a la televisión en particular. "Esas eran las ventanas de acceso de los factores y los actores políticos no solo a cada uno de los hogares, sino a cada uno de los ciudadanos. Los medios sociales surgieron para redefinir esa hegemonía. Ese privilegio, ese poder, hoy está desconfigurado" (Galup, 2019, p. 64).

Este cambio de roles modifica la esfera pública, generando relaciones más diversas entre los actores políticos, la ciudadanía y los medios de comunicación. Como señala Suiter (2016) el actual ecosistema mediático está dominado por el reality-show, los medios sociales y la existencia de burbujas que filtran la información (filter bubbles). En este escenario, el estudio de la desinformación se hace absolutamente necesario, porque significa un problema que impacta en la base de los sistemas democráticos y en las acciones políticas de la ciudadanía. 
Desde los diferentes enfoques teóricos que abordan el tema durante los últimos años, prevalece la diversidad de términos para denominar a aquellas informaciones que son engañosas, falsas o erróneas y que están constituidas de ese modo de manera deliberada. Durandin (1995) es de los primeros interesados en clasificar aquellas acciones que pueden considerarse desinformativas: eliminar o silenciar la totalidad de la información; alterar informaciones (manipulación informativa); e inventar acontecimientos. Para el autor, estos fenómenos son básicamente conjuntos organizados de engaños. Otros, sin embargo, consideran que en cualquier desinformación pervive una información. Es decir, cualquier contenido vago, engañoso o ambiguo, puede llegar a resultar informativo (Karlova y Lee, 2011). La desinformación guarda una relación de causalidad con el tratamiento periodístico de la información cuando se produce un incumplimiento manifiesto de las normas éticas de la profesión (Murolo, 2019). Como indica Gelfert (2018) las noticias falsas son la presentación deliberada de reclamos falsos o engañosos como noticias, donde el periodismo falla en la verificación antes de su publicación y difusión.

Hazard-Owen (2017) considera que lo que caracteriza el éxito de una noticia falsa es que esté dirigida a las emociones, tener apariencia de legitimidad, tener una publicación efectiva en Internet y ser amplificada en la red (como Twitter o Facebook).

Aunque es un fenómeno contra el cual el periodismo viene luchando desde hace décadas (Burnam, 1975; Galdón, 1994), la difusión de noticias falsas, o desórdenes informativos, cobraron una nueva dimensión con la consolidación de las redes sociales. Esto provoca que la problemática de las fake news ascienda a una escala transnacional. La amplitud y rapidez en la difusión de estas (des)informaciones, obligó a que gobiernos, entidades del tercer sector y organismos internacionales, se ocupen de establecer parámetros de detección de contenidos deliberadamente falsos, con el objetivo de disminuir su difusión. La sociedad digital propicia un ágora casi sin regulación estatal ${ }^{3}$, pero con fuerte presencia de intervención privada ${ }^{4}$, donde el anonimato y la opacidad de las fuentes que generan la información constituyen el territorio ideal para la difusión y viralización de todo tipo de contenidos.

Una de las maneras más populares para denominar estos contenidos es considerarlos fake news, siguiendo la expresión popularizada por Quandt et al. (2019) luego de las elecciones presidenciales de EEUU en el 2016 que enfrentó a Donald Trump y a Hillary Clinton, siendo vencedor el primero. A esta manera de denominar este fenómeno de desinformación se suman otras, tales como "desorden informativo", considerado así en informes realizados por organismos como la Comisión Europea o incluso la Unesco (Ireton y Possetii, 2018).

Calvo y Aruguete (2020) sugieren abordar estos fenómenos de desinformación según su intencionalidad y distinguen la noticia falsa o false news, de la fake news. En el castellano contamos sólo con el adjetivo "falso" pero si se lo piensa como false news, sería una noticia que desinforma sin la intencionalidad de desinformar, es decir, es

\footnotetext{
${ }^{3}$ Recientemente, el parlamento australiano intervino a través de una ley para que tanto Facebook como Google compensen los ingresos publicitarios que los medios de comunicación dejaron de percibir en favor de las plataformas que, a su vez, se benefician de los contenidos que estos medios producen.

${ }^{4}$ Al respecto, un caso para analizar es la eliminación de las cuentas de Donald Trump luego del asalto de sus seguidores al Capitolio el 6 de enero de 2021.
} 
producto de una confusión o un error. A diferencia de ésta, la fake news es creada con la intencionalidad de provocar y principalmente, desestabilizar el sistema político. Es allí donde los tres elementos más importantes de la comunicación política se encuentran: los políticos, los medios y la opinión pública. Si la opinión pública consume información falsa dada por los medios o plataformas sobre los actores políticos, el sistema se corrompe (Quintana Pujalte, 2020).

Más allá de la polisemia y los problemas metodológicos que significa su falta de consenso en la denominación y cómo enmarcar el fenómeno (Alemanno, 2018), desde este estudio se suscribe considerar a estos desórdenes informativos con la definición de bulo, entendido como "todo contenido intencionalmente falso y de apariencia verdadera, concebido con el fin de engañar a la ciudadanía y difundido públicamente por cualquier plataforma o medio de comunicación social" (Salaverría et al., 2020, p. $4)$.

Para López-Borrull et al. (2018) la mejor manera de combatir este problema en la sociedad digital es buscar mayor acceso a la información y a la posibilidad de verificación de los contenidos. Las plataformas pusieron a disposición de los usuarios distintas herramientas de verificación de información durante la crisis del coronavirus. Por mencionar algunos casos: Google reverse, permite verificar el origen aproximado de las imágenes que circulan en la red. Con la misma facilidad que se puede buscar información en el sitio, se puede subir una imagen y corroborar la fecha y lugar donde pudo haberse tomado. El sistema funciona mediante ClaimReview, un verificador de contenidos externo a la compañía. La plataforma Twitter estableció un aviso que muestra a los seguidores si se retuitea un contenido sin haber ingresado antes en el enlace, así como también una alerta que destaca si la información que forma parte del tuit es errónea o cuestionable. También endureció su seguimiento a cuentas falsas.

En esa misma línea, Facebook buscó limpiar su imagen luego del escándalo de Cambridge Analytica y el tráfico de datos durante las elecciones de EEUU de 2016, y estableció un sistema para evitar la viralización de noticias falsas a través de su programa de fact-checking que se gestiona por parte de terceros ajenos a Facebook, con el fin de combatir los bulos que circulan dentro de su plataforma. Además, generó un aviso a los usuarios cuando éstos establecen alguna interacción con contenidos falsos, gracias al desarrollo de una tecnología de algoritmos encargados de detectar informaciones falsas o engañosas. A su vez, la plataforma de mensajería WhatsApp determinó un límite a la cantidad de mensajes que podían ser reenviados, con el objetivo de bajar los niveles de viralización de contenido.

\subsection{Plataformas de verificación}

Existe un notable esfuerzo desde distintas entidades para poder dar batalla con los bulos informativos que se propagan por medios y redes socio-digitales. Se pueden mencionar algunos ejemplos: la Unión Europea cuenta con una acción de vigilancia para combatir las fake news que se dan dentro de su territorio; la ONU cuenta con una iniciativa denominada Verified que también busca la colaboración ciudadana para la denuncia de informaciones falsas; agencias de noticias disponen ya de un área específica de verificación de informaciones y desde septiembre de 2015, se ha creado la Red Internacional de Verificación de Datos (IFCN por sus siglas en inglés), una 
unidad del Instituto Poynter dedicada a reunir a verificadores de datos en todo el mundo. Actualmente son setenta y cuatro las organizaciones que forman parte de esta red, provenientes de setenta países y realizan chequeos en cuarenta idiomas. Su función es la de verificar declaraciones de figuras públicas, instituciones importantes y otras afirmaciones de interés para la sociedad de amplia circulación. Ufarte-Ruiz et al. (2020, p. 24) definen al fact-checking como "una práctica periodística basada en la comprobación a posteriori de informaciones publicadas por los medios de comunicación y en la verificación de las declaraciones o comentarios realizados por líderes políticos o personajes relevantes".

El ejercicio de verificación se hace esencial en el contexto digital actual, donde son frecuentes los problemas de difusión de información falsa, como se ha mencionado en el apartado anterior. La ciudadanía necesita herramientas a su alcance que le permita identificar rápidamente cuando está expuesta a una noticia falsa, y que pueda también tener los elementos suficientes para distinguir ese tipo de desinformaciones de las noticias verdaderas.

La práctica de verificación de datos se potencia con las herramientas que ofrece la tecnología, que permite un acceso a los datos de manera más acelerada, lo cual repercute en que el público acceda a información de mejor calidad. Entre las herramientas más utilizadas por los fact-checkers se encuentra Google image reverse, que como se ha mencionado, sirve para conocer el origen aproximado de una imagen que circula por la red. Para buscar información sobre imágenes también se utiliza la herramienta del buscador Bing y la aplicación TinEye.

Para conocer en qué red social se está produciendo una mayor interacción de un contenido sospechoso de ser falso se utiliza Buzzsumo, que permite evaluar los contenidos más populares. CrowdTangle es otra herramienta de utilización frecuente, pero tiene como limitación que sólo permite observar contenidos en Facebook, ya que corresponde a esta plataforma. Ofrece datos como el promedio de interacción de una publicación, en relación a la que tienen otras publicaciones del mismo usuario. Otra herramienta gratuita es TweetDeck, corresponde a Twitter, y también permite filtrar datos sobre publicaciones que se comparten a través de esta plataforma. Las mencionadas son solo algunas de las herramientas que se utilizan desde el factchecking, y lo que tienen de interesante, es que muchas de éstas son accesibles para el público en general. También es evidente que estas iniciativas de búsqueda y control de contenidos falsos se dan en estos canales porque es donde en la actualidad surgen muchos de los contenidos con los que los fact-checkers deben lidiar diariamente.

La cantidad de plataformas de verificación aumenta a un ritmo acelerado, el Instituto Reuters destacaba este crecimiento sostenido en un estudio realizado durante 2016 , donde se hacía referencia al éxito que las mismas estaban teniendo alrededor del mundo (Graves y Cherubini, 2016). La Universidad de Duke ofrece un reporte anual de estas plataformas y los datos indican que ya hay más de 300 iniciativas en todo el mundo, con nuevas propuestas que aparecen año tras año. Sudamérica se erige como la región donde más plataformas de verificación se han inaugurado en el último año (Duke's University, 2020). 
De cara a la crisis sanitaria y la proliferación de desinformación, una red de verificadores de datos de América Latina que colabora con la IFCN, decidió llevar a cabo un proyecto "para chequear información, recopilar y actualizar verificaciones en español sobre el coronavirus, además de producir una base de datos con información sobre las medidas tomadas por los gobiernos de la región" (Estarque, 2020). La red bautizada LatamChequea, nuclea a veintiocho entidades que se dedican a la verificación con sede en dieciséis países de Latinoamérica y en España. Su objetivo es "ayudar a periodistas y verificadores en la cobertura del coronavirus, para que puedan encontrar información confiable de manera más rápida y sencilla".

La red está coordinada por Chequeado de Argentina y participan: AFP Factual, Salud con Lupa; Aos Fatos, Estadao Verifica y Lupa de Brasil, Bolivia Verifica, Mala Espina Check de Chile, La Silla Vacía y ColombiaCheck de Colombia, \#NoComaCuento (La Nación) y La Voz de Guanacaste de Costa Rica, Periodismo de Barrio y El Toque de Cuba, Ecuador Chequea y GK de Ecuador, EFE Verifica, Maldita y Newtral de España, Agencia Ocote de Guatemala, Animal Político, Spondeo Media y Verificado de México, Despacho 505 y La Lupa de Nicaragua, El Surtidor de Paraguay, Convoca, OjoPúblico y Verificador (La República) de Perú, Observador y Polígrafo de Portugal, PoletikaRD de República Dominicana, UyCheck de Uruguay y Cotejo.info, Efecto Cocuyo y EsPaja de Venezuela. Además de ofrecer una base de datos con las verificaciones y chequeos, comparten otro documento con las medidas tomadas en cada país para contrarrestar la crisis sanitaria del coronavirus en la región.

Está claro que tanto el perfil periodístico que se enfoca en los datos como en la verificación, constituyen un espacio de permanente cambio y adaptación para combatir las noticias falsas (Graves, Brendan y Reifter, 2015). La mejor respuesta al fenómeno de la desinformación no es la censura, sino el fact-checking (Rodríguez, 2020).

\section{OBJETIVOS}

Este estudio tiene como objetivo analizar los contenidos difundidos en América Latina que fueron desmentidos por las plataformas de verificación que conforman LatamChequea entre febrero y septiembre de 2020, y que se encuentran disponibles en la base de datos disponible en su sitio web. En el proceso de análisis, se busca reconocer el trabajo de fact-checking que se realiza desde este equipo, así como identificar la tipología de contenidos que fueron tratados por estos verificadores. Finalmente, se pretende reflexionar sobre la lógica latente que constituye a estas desinformaciones.

\section{METODOLOGÍA}

La investigación que aquí se presenta es mixta, ya que se realiza un abordaje de tipo cuantitativo respecto de los contenidos en análisis, y se identifican además ciertos rasgos relevantes de éstos, que, al ser descritos, complementa el análisis con una mirada cualitativa. El objeto de estudio son aquellos contenidos que han sido verificados por la plataforma LatamChequea y que figuran como tales en su sitio web. La observación se realiza entre el 27 de febrero y el 25 de septiembre de 2020 . Este tiempo representa los primeros siete meses de desarrollo de la pandemia por Covid- 
19, así como también coincide con la inauguración de la plataforma que busca contrarrestar con los contenidos falsos y virales en Latinoamérica específicamente vinculados a la crisis sanitaria del coronavirus. La base de datos que ofrece la plataforma está compuesta por verificaciones realizadas por las agencias de verificación que forman parte de esta red de verificadores, lo cual conforma el universo de análisis. Se han excluido aquellos contenidos que corresponden a otros países no latinoamericanos, como España y Portugal.

El método que guía este estudio es el análisis de contenido abordaje que buscará desgranar los componentes de estos discursos virales. Desde este enfoque, se establecieron cuatro categorías para identificar en los contenidos: 1) Países donde se realizaron las verificaciones; 2) temáticas desmentidas (compuesta por las dimensiones ciencia/salud, política/gobierno, otros); 3) Presencia de contenido desmentido en varios países; 4) Origen del contenido viral (cuyas dimensiones son Facebook, WhatsApp, Twitter, redes sociales genéricas, medios de comunicación, Instagram, Youtube, Email, web de gobierno, SMS, Telegram). A partir del análisis de estas categorías el estudio pretende responder a las siguientes preguntas de investigación: RQ1: ¿Qué tipo de desinformaciones fueron viralizadas y desmentidas por la plataforma LatamChequea durante los primeros meses de la pandemia?, y RQ2: ¿Dónde se originan y cómo operan estas desinformaciones verificadas por la plataforma?

\section{DISCUSIÓN}

Del total de 3108 datos que se disponen en la web de LatamChequea, 2353 informaciones que pasaron por un proceso de verificación corresponden a países de América Latina, mientras que el resto son de España y Portugal. Como se ha mencionado en la metodología, se han descartado los datos correspondientes a la península ibérica como países de origen de la desinformación. La región cuenta entonces con 2353 informaciones chequeadas en la plataforma, lo cual incluye noticias falsas, engañosas así como chequeos que derivaron en comprobar la veracidad de los dichos analizados. LatamChequea ha verificado informaciones que fueron identificadas como falsas, engañosas, fuera de contexto o inconsistentes en dieciséis países de la región. 


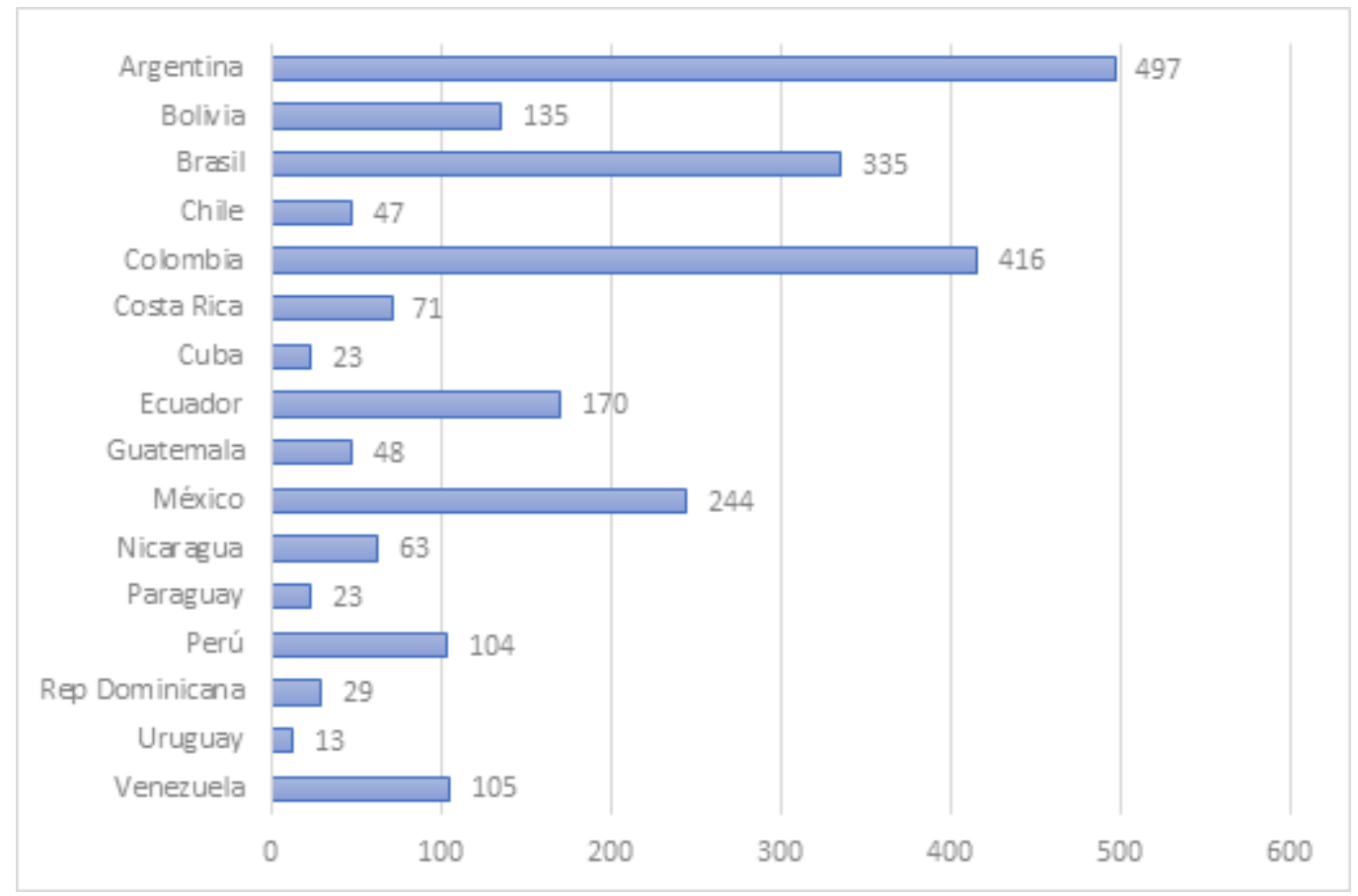

Figura 1: Informaciones desmentidas y chequeadas entre el 27/02 y el 25/09 en LatamChequea

Fuente: LatamChequea

Como se puede observar en la figura 1, Argentina y Colombia fueron los territorios donde se desmintieron la mayor cantidad de informaciones (497 y 446, respectivamente). Seguidos de Brasil y México (335 y 244, respectivamente). Cabe aclarar que los datos tienen el sesgo correspondiente a que son informaciones que pasaron por el filtro de chequeo de la plataforma, es decir, que son informaciones que fueron verificadas.

Sobre estos datos, es relevante también conocer las temáticas que se hicieron virales. La plataforma cuenta con una clasificación propia en la que denomina "tipo de contenido"; sin embargo, en muchos casos estos contenidos pueden englobarse en una tipología más simple. Para este estudio se han establecido tres dimensiones que han sido finalmente codificadas en la categoría de temáticas desmentidas en el análisis de contenido, entre ellas (A) ciencia/salud; (B) política/gobierno y (C) otros (Salaverría et al., 2020). 


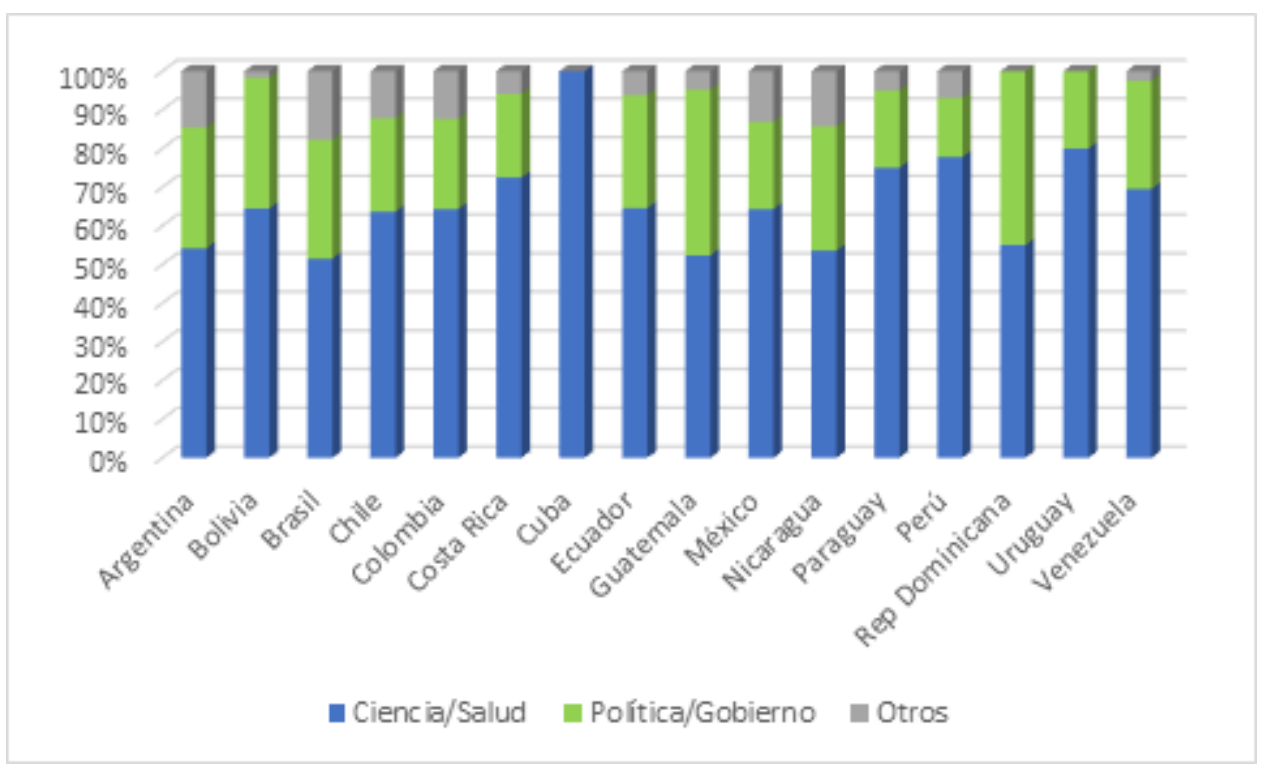

Figura 2: Temáticas de las informaciones verificadas y desmentidas Fuente: LatamChequea

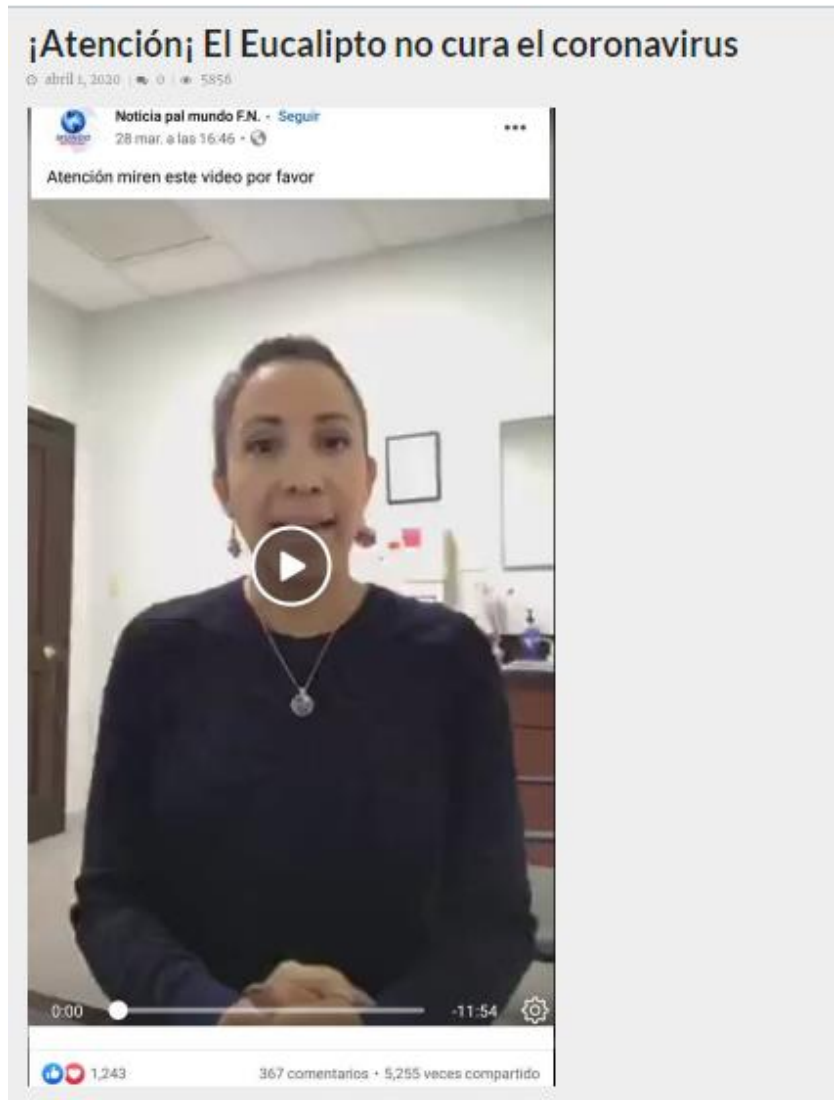

Figura 3: Captura de pantalla de desmentida por Bolivia Verifica, de Bolivia Fuente: LatamChequea

Como es de esperar por el contexto de pandemia por Covid-19, las temáticas vinculadas a la salud y la ciencia tomaron un alto protagonismo en la viralización de contenido falso o engañoso, sobre un total de 1795 informaciones que fueron 
marcadas como falsas o engañosas tras ser analizadas en la plataforma de LatamChequea. La figura 3 muestra un chequeo a cargo de Bolivia Verifica. Desde la plataforma indican que este video fue publicado el 28 de marzo de 2020 a las 16:46 en la página de Facebook "Noticia pal mundo N.F." de Republica Dominicana, se compartió más de 5.500 veces en diferentes grupos de Facebook, también tiene más de 350 comentarios y más de 1300 interacciones Este mismo contenido también se desmintió desde Colombia, México y Costa Rica5.

Otro aspecto llamativo de estos bulos es su capacidad de traspasar fronteras. Como se puede observar a continuación, el mismo tipo de contenido falso o engañoso, se viralizó en varios países.

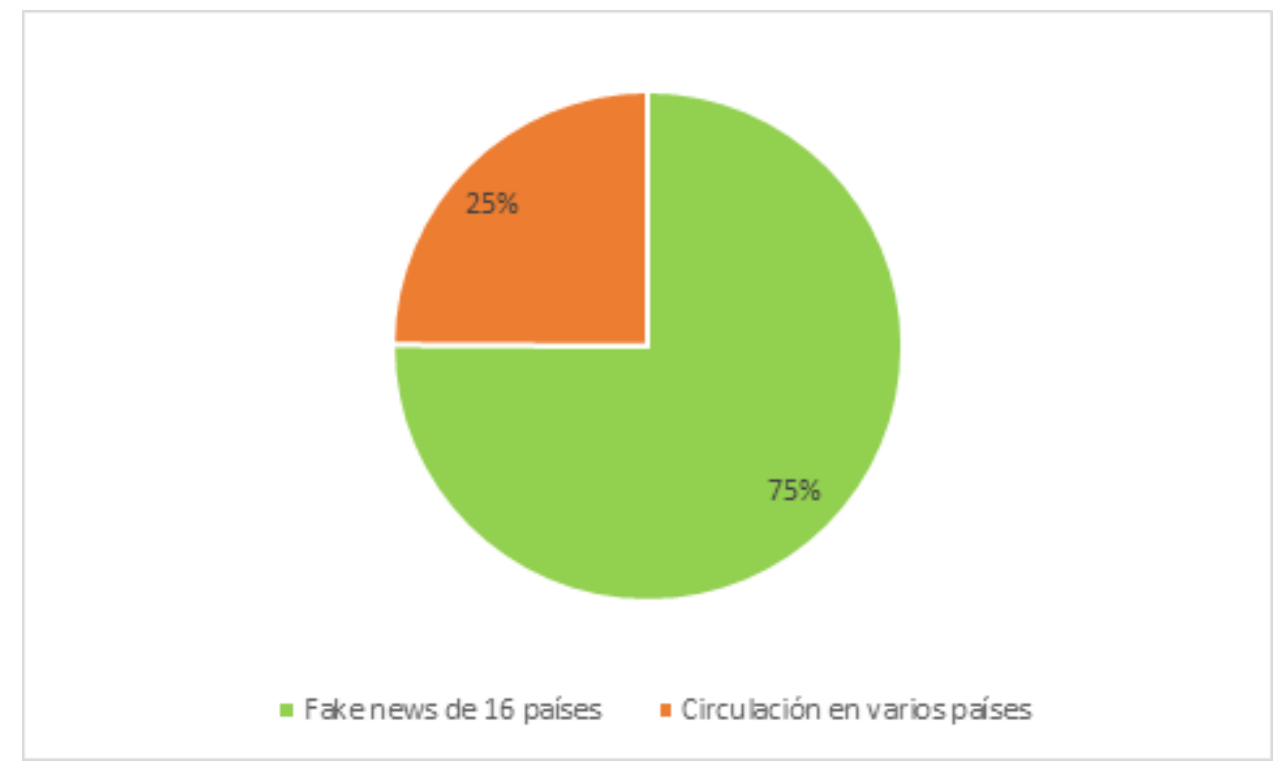

Figura 4: contenidos iguales viralizados en varios países

Fuente: LatamChequea

En concreto, $25 \%$ del total de noticias falsas o engañosas difundidas en estos 16 países y que han pasado por el filtro de un chequeo en esta plataforma, se han viralizado también en otros países. Un caso singular ha sido el de la vinculación de la tecnología 5G con la propagación del virus, esto es particularmente llamativo ya que la tecnología aún no está operativa en la mayoría de los países de Latinoamérica (De la Torre, 2020)

La noticia falsa que relaciona la presencia de la tecnología $5 \mathrm{G}$ con la transmisión del virus Covid-19 y la indica como causante de síntomas de gripe circuló por WhatsApp y la publicación en Facebook (según datos de Chequeado Argentina) fue compartida más de 1000 veces en un chequeo publicado el 21 de abril. Ya a principios de abril, Youtube prohibió los videos que hacen afirmaciones falsas sobre la relación entre la $5 \mathrm{G}$ y la pandemia por Covid- 19.

${ }^{5}$ Desmentida de Bolivia verifica sobre las supuestas propiedades del eucalipto para combatir el coronavirus en https://bit.ly/3tPliGJ; desde Animal político también hicieron lo propio, https://bit.ly/3vYZJBQ desde La Silla vacía, de Colombia https://bit.ly/3vPcFKe y también desde No coma cuento, de Costa Rica: https://bit.ly/3tUtJfZ 
Otro ejemplo identificado ha sido la difusión y viralización en varios países de una supuesta medida de contención del virus realizada por la administración de Vladimir Putin en Rusia, en la que se afirmaba que para que la gente se quede en sus casas, se lanzaron leones a las calles rusas ${ }^{6}$. Esta información fue desmentida por las entidades de verificación de al menos México, Colombia y Argentina. En este caso la información surgió en un generador de memes que simulan noticias denominado The Breaking News Generator, sin embargo, muchos usuarios no comprendieron la broma y compartieron este contenido como si fuese una medida real de contención del virus.

El origen de los contenidos que se hacen virales es otro rasgo que permite conocer el modo en que operan estas informaciones para poder llegar a un mayor número de personas. En este sentido, las redes sociales funcionan como un gran caldo de cultivo para la difusión de informaciones de baja rigurosidad y hasta incluso mentiras que se difunden adrede para desestabilizar o poner en duda verdades científicas como el rol de la vacunación o los modos en los que se transmiten los virus y bacterias.

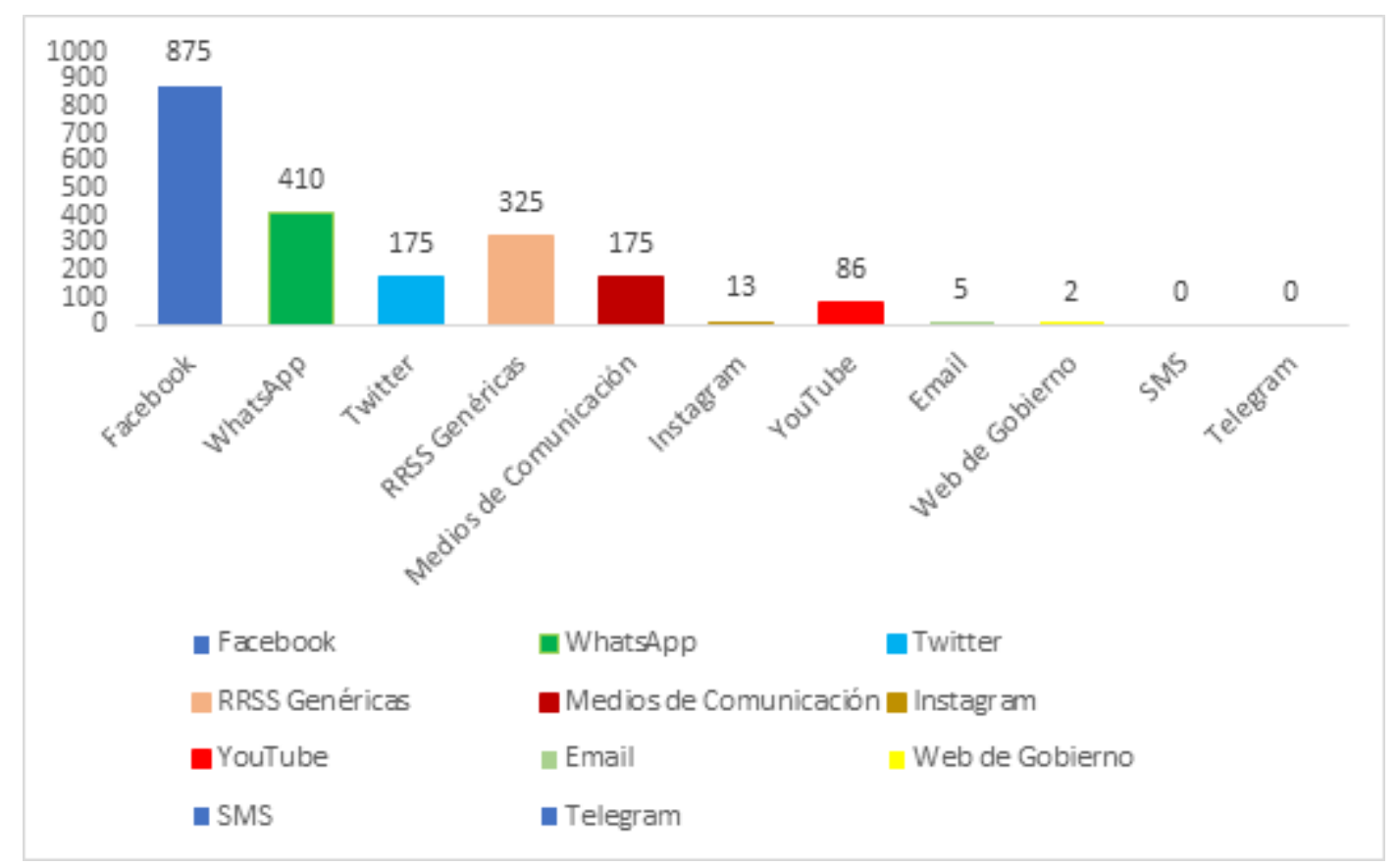

Figura 5: origen de los contenidos viralizados

Fuente: LatamChequea

Los datos demuestran que Facebook es la plataforma desde donde con mayor frecuencia se comparten y viralizan contenidos que han sido verificados y desmentidos por la plataforma de LatamChequea. También puede observarse que es significativa la presencia de WhatsApp para la viralización de estos contenidos. Esto ya ha sido detectado por las plataformas las cuales han buscado la manera de regular la presencia de contenidos falsos en sus aplicaciones. Desde abril de 2020 WhatsApp, por ejemplo, ha limitado la cantidad de veces que un contenido puede ser reenviado

\footnotetext{
${ }^{6}$ Colombia check desmintió esta información, haciendo referencia a que se difundió en otros países, https://bit.ly/2OWKIzM, también lo hizo Animal Político de México https://bit.ly/3d23g9N, y Bolivia verifica: https://bit.ly/3w6nPKW
} 
a los contactos (incluso aparece el mensaje "reenviado muchas veces" acompañando al texto y/o imagen), y Facebook inauguró también una verificación externa que le permite no solo controlar los contenidos, sino también bloquear cuentas o eliminarlas (Rosen, 2020).

Otro dato interesante que arrojan los resultados del estudio es que es relativamente alto el rol de los medios tradicionales como origen de una información que ha sido verificada y luego desmentida. Se equipara con aquellas desmentidas que tuvieron como origen Twitter, una plataforma que aún no cuenta con estrategias de verificación consolidadas, a diferencia de los medios masivos de comunicación. La calidad informativa ha guiado el compromiso del periodismo con su rol en la sociedad y con estos indicadores negativos, se refleja cierta crisis en las rutinas periodísticas de verificación de información (Alonso-González, 2019).

\section{CONCLUSIONES}

El estado actual de las informaciones que fueron consideradas falsas o engañosas en LatamChequea demuestra que cuatro países tienen los índices más altos de informaciones desmentidas o chequeadas: Argentina, Colombia, Brasil y México. Durante los meses de análisis, el $62 \%$ de las informaciones desmentidas en América Latina tuvieron que ver con cuestiones de índole de ciencia y salud, $27 \%$ a política y gobierno y $11 \%$ a otros temas. Esto sugiere que los contenidos de tipo político encontraron una considerable expresión entre las informaciones falsas viralizadas. Incluyendo a actores políticos de relevancia, e incluso, siendo estos mismos actores los generadores de informaciones falsas o engañosas. Por mencionar un caso singular, el del presidente de Argentina Alberto Fernández, quien en una entrevista aseguró que la OMS recomienda tomar bebidas calientes porque el calor mata al virus . Este actor político central de la esfera pública fue un difusor más de contenidos falsos, que según los datos de LatamChequea, circularon por España, Hong Kong y Colombia. Otro caso fue un contenido falso que implicaba al presidente de Colombia Ivan Duque. Un senador del Centro Democrático, Carlos Felipe Mejía, compartió información que aseguraba que Duque era el tercer mandatario a nivel mundial en tomar mejores medidas de contención contra el covid-19. La información falsa tuvo más de 700 interacciones sólo en Twitter, y fue replicada por medios colombianos.

También demuestra que muchos contenidos encuentran espacio de expresión y viralización en distintos países, lo que evidencia la transversalidad de los contenidos virales. Facebook sigue siendo la plataforma donde en mayor medida se generan y viralizan las fake news. Sin embargo, con frecuencia, los medios tradicionales caen en la misma lógica débil de chequeo propia de las redes sociales.

Experiencias de regulación como se pueden encontrar en Asia, exigen la necesidad de observar de qué manera no se restringen libertades individuales. En Brasil existen iniciativas recientes que buscan entrar en el ámbito de la discusión sobre el tema, pero carecen de una definición concreta de lo que pueden ser consideradas fake news o no. En Argentina el gobierno está construyendo un ente autárquico denominado Nodio, con el objetivo de combatir las noticias falsas y los discursos de odio. Incluso investigadores e investigadoras del Conicet (el principal organismo de Ciencia y Tecnología nacional de Argentina) crearon un proyecto denominado "Ciencia Anti- 
Fake News Covid-19", donde desmintieron más de 100 noticias falsas. Algunas agencias de noticias nacionales latinoamericanas (en México y en Argentina) han creado dentro de la agencia oficial del gobierno un sector dedicado al tema de desinformación. El caso es que al observar los chequeos, hay pocos o ninguno, sobre cuestiones del propio gobierno. De manera que el debate sobre la regulación puede ser un camino, pero es evidente que exige a la par un profundo debate sobre la libertad de expresión. El fortalecimiento de las organizaciones que se dedican a chequear información debe ser un compromiso transnacional, porque son herramientas que permiten generar pedagogía en las audiencias, lo cual colabora en una mejor expresión de la ciudadanía informada.

Tal como se ha desarrollado en la introducción de este artículo, el contexto comunicativo se muestra condicionado por la desinformación. Este escenario exige la colaboración de estas organizaciones en la verificación de información para desmontar las estrategias de las noticias falsas, y así facilitar el acceso a información veraz, tanto para la ciudadanía como para los medios. Esto debe ir de la mano de un fuerte compromiso para señalar cómo operan estas (des)informaciones, tanto para la ciudadanía como para los responsables de medios de comunicación. Asimismo, exigir la apertura de datos, a los que se pueda acceder libremente para contrarrestar discursos, otorgarían más herramientas para combatir las trampas de las noticias falsas. Aunque la consolidación de las plataformas de verificación a nivel global es un dato alentador, resta mucho camino aún para lograr mayor conciencia respecto de cómo combatir estos fenómenos de desorden informativo.

\section{REFERENCIAS}

Alemanno, A. (2018). Editorial: How to counter fake news? A taxonomy of anti-fake news approaches. European journal of risk regulation, 9, 1-5. https://doi.org/10.1017/err.2018.12

Alonso González, M. (2019). Fake News: desinformación en la era de la sociedad de la información. Ámbitos. Revista Internacional de Comunicación 45, 29-52. https://doi.org/10.12795/Ambitos.2019.i45.03

Bernays, E. (1928). Propaganda. New York: Horace Liveright.

Brennen, J. S., Simón, F., Howard, P. y Nielsen, R. (2020). Types, sources, and claims of Covid-19 misinformation. Reuters Institute for the Study of Journalism Factsheet, abril 2020, pp. 1-13. https://reutersinstitute.politics.ox.ac.uk/types-sources-andclaims-covid-19-misinformation

Bryant, D. C. (1953). Rhetoric: Its functions and its scope. Quarterly Journal of Speech, 90, 189-211 https://doi.org/10.1080/00335635309381908

Burnam, T. (1975). The dictionary of misinformation. New York: Thomas Y. Crowell

Calvo, E. y Aruguete, N. (2020). Fake news, trolls y otros encantos. Como funcional (para bien y para mal) las redes sociales. Buenos Aires: Siglo XXI 
De la Torre, K. (2020, 3 de enero). Los retos de Latinoamérica para adoptar la red 5G, LexLatin. https://bit.ly/3bQmyzE

Debord, G. (1967): La société du spectacle. Paris: Buchet-Chastel.

Delli Carpini, M. X. y Williams, B. A. (2011). After broadcasting news. Nueva York: Cambridge

Doob, L. (1950). Goebbels, principles of propaganda. The Public Opinion Quarterly, 14 (3), 419-442. https://www.jstor.org/stable/2745999

Duke's University (2020). Reporter's Lab. Fact-Checking. Duke University. https://reporterslab.org/latest-news/

Durandin, G. (1995). La desinformación, la información y la realidad. Madrid: Paidos

Estarque, M. (2020, 15 de abril). Proyecto colaborativo de fact-checking en América Latina crea plataforma sobre el coronavirus para ayudar a periodistas, LatamJournalism Review. https://bit.ly/3stN9sp

Freud, S. (2013). Más Allá del Principio de Placer, Psicología de las Masas y Análisis del Yo, y Otras Obras (1920-1922). Buenos Aires: Amorrortu.

Galdón, G. (1994). Desinformación: método, aspectos y soluciones. Pamplona: Eunsa.

Galup, L. (2019) Big data y política. De los relatos a los datos. Persuadir en la era de las redes sociales. Buenos Aires: Ediciones B.

Gelfert, A. (2018). Fake news: A definition. Informal Logic, 38(1), 84-117. https://doi.org/10.22329/il.v38i1.5068

Graves, L., \& Cherubini, F. (2016). The Rise of Fact-checking Sites in Europe. Oxford, United Kingdom: University of Oxford. https://reutersinstitute.politics.ox.ac.uk/ourresearch/rise-fact-checking-sites-europe

Graves, L., Brendan, N., y Reifler, J. (2015). The Diffusion of Fact-checking. Understanding the growth of a journalistic innovation. United States: American Press Institute.

Hazard-Owen, L. (2017). Noticias reales sobre noticias falsas: Facebook se asocia con más sitios de fact-checking. Red Internacional de Periodistas. https://bit.ly/3tXgsUg

Ireton, C. y Posetti, J. (2018). Journalism, 'fake news' \& disinformation: handbook for journalism education and training. París: Unesco Publishing. https://en.unesco.org/sites/default/files/journalism fake news disinformation print friendly 0 0.pdf 
Jerábek, H. (2011). Merton and Lazarsfeld: Collaboration on Communication Research-Two Papers, Two Research Instruments, and Two Kindred Concepts Sociologický Časopis / Czech Sociological Review. 47 (6), 1191-1214. https://www.jstor.org/stable/23535019

Karlova, N. y Lee, J. (2011). Notes from the underground city disinformation: A conceptual investigation. Proceedings of the American Society for Information $\begin{array}{lllll}\text { Science } \quad \text { and } & \text { Technology, } & 48 & \text { (1), }\end{array}$ https://doi.org/10.1002/meet.2011.14504801133

Lasswell, H. D. (1927) The Theory of Political Propaganda. American Political Science Review, 21 (3), 627-631. https://doi.org/10.2307/1945515

Le Bon, G. (1947): The Crowd: A Study of the Popular Mind. Library of Alexandria.

López-Borrull, A., Vives-Gràcia, J., y Badell, J. (2018). Fake news, ¿amenaza u oportunidad para los profesionales de la información y la documentación?. El profesional de la información, 27(6), 1346-1356. https://doi.org/10.3145/epi.2018.nov.17

Marcuse, H. (1964). El hombre unidimensional. México: Ariel

Murolo, L. (2019). La posverdad es mentira. Un aporte conceptual sobre periodismo y fake news. In Aparici, R., y García Marín, D. (Coords.), La posverdad. Una cartografía de los medios, las redes y la política (31-42). Barcelona, España: Gedisa.

Nielsen, R., Fletcher, R., Newman, N., Brennen, J. y Howard, P. (2020). Navigating the 'Infodemic': How people in six countries access and rate news and information about coronavirus. Oxford: Reuters Institute for the Study of Journalism. https://cutt.ly/ryTKzYp

Owen, D. (2018). El papel de los nuevos medios en la política. En AAVV (2018), La era de la perplejidad. Madrid: Taurus. https://bit.ly/2095FSM

Pérez-Dasilva, J., Meso-Ayerdi, K., Mendiguren-Galdospín, T. (2020). Fake news y coronavirus: detección de los principales actores y tendencias a través del análisis de las conversaciones en Twitter. El profesional de la información, 29 (3). https://doi.org/10.3145/epi.2020.may.08

Pérez Tornero, J. M., Samy Tayie, S., Tejedor, S. y Pulido, C. (2018). ¿Cómo afrontar las noticias falseadas mediante la alfabetización periodística? Estado de la cuestión. Doxa Comunicación, 26, 211-235. https://doi.org/10.31921/doxacom.n26a10

Quandt, T., Frischlich, L., Boberg, S. y Schatto-Eckrodt, T. (2019). Fake news. The international encyclopedia of journalism studies, pp. 1-6. https://doi.org/10.1002/9781118841570.iejs0128 
Quintana Pujalte, L. (2020). El discurso político en Twitter: análisis de la comunicación de las fórmulas presidenciales argentinas en 2019. De prácticas y discursos, 9(14). https://bit.ly/3nL9f5V

Rodríguez, C. (2020). Una reflexión sobre la epistemología del fact-checking journalism: retos y dilemas. Revista de Comunicación, 19(1), 243-258. https://doi.org/10.26441/RC19.1-2020-A14

Romero-Rodríguez, L. (2013). Hacia un estado de la cuestión de las investigaciones sobre desinformación /misinformación, Correspondencias \& Análisis (3), 319-342, https://doi.org/10.24265/cian.2013.n3.14

Rosen, G. (2020, 16 de abril). An update on our work to keep people informed and limit misinformation about Covid-19. https://about.fb.com/news/2020/04/covid-19$\underline{\text { misinfo-update }}$

Salaverría, R., Buslón, N., López-Pan, F., León, B., López-Goñi, I. y Erviti, M. (2020). Desinformación en tiempos de pandemia: tipología de los bulos sobre la Covid-19. El profesional de la información, 29(3). https://doi.org/10.3145/epi.2020.may.15

Schiller, H. (1987). Los manipuladores de cerebros. Barcelona: Gedisa

Suiter, J. (2016): Post-truth Politics Political Insight, 7(3), 25-27. https://doi.org/10.1177/2041905816680417

Ufarte-Ruiz, M. J., Anzera, G. y Murcia-Verdú, F. J. (2020). Plataformas independientes de fact-checking en España e Italia. Características, organización y método. Revista Mediterránea de Comunicación, 11(2), 1-17. https://www.doi.org/10.14198/MEDCOM2020.11.2.3

Wardle, C. (2019). First draft's essential guide to understanding information disorder. First draft. October. $\quad$ https://firstdraftnews.org/wpontent/uploads/2019/10/Information Disorder Digital AW.pdf

\section{AUTORES}

\section{Leticia Quintana Pujalte}

Universidad de Málaga (UMA, España). Doctora en Comunicación por la Universidad de Málaga. Su línea de investigación está vinculada a la Comunicación Política. Es Magister en Gestión Estratégica e Innovación en la Comunicación (UMA), Licenciada en Comunicación Social por la Universidad Nacional del Nordeste (Argentina). Ex becaria doctoral de AUIP, y exprofesora universitaria en la cátedra de Opinión Pública (UNNE)

l.quintanapujalte@uma.es

ORCID: https://orcid.org/0000-0002-1834-283X

Academia: https://independent.academia.edu/LeticiaQuintanaPujalte

ResearchGate: https://www.researchgate.net/profile/Leticia Quintana Pujalte 


\section{María Florencia Pannunzio}

Universidad Nacional del Nordeste (UNNE, Argentina). Doctora en Comunicación (UNLP-Arg). Licenciada en Comunicación Social (UNNE-Arg). Investigadora del Centro de Estudios Sociales de la Universidad Nacional del Nordeste (UNNE) en temáticas de juventudes, participación y apropiación de tecnologías digitales. Docente en las cátedras Teorías de la comunicación social 1 e Investigación en comunicación de la Licenciatura en comunicación social (Facultad de Humanidades, UNNE).

florencia.pannunzio@comunidad.unne.edu.ar

ORCID: https://orcid.org/0000-0001-5587-1936 